\title{
Tension Hemothorax: A Rare Complication and How to Avoid It
}

\author{
Gaurav Sundar ${ }^{1}$ Pradesh Kumar $^{1}$ \\ 1 Department of Radiology, Aintree University Hospital, \\ Liverpool, United Kingdom
}

J Clin Interv Radiol ISVIR 2017;1:190-191.
Address for correspondence Gaurav Sundar, MD, FRCR, Department of Radiology, Aintree University Hospital, Longmoor Lane, Liverpool L9 7AL, United Kingdom (e-mail: gaurav.sundar@aintree.nhs.uk).
We would like to share our experience with an interesting case we recently treated involving an iatrogenic tension hemothorax. It occurs because of uncontrolled arterial bleeding into the thoracic cavity, resulting in rapid increase in intrathoracic pressure. The source of bleeding can be the aorta or intercostal artery and may occur from rib fractures, iatrogenically during surgery or even spontaneously in patients on anticoagulant therapy. The rapid accumulation of blood in the chest cavity can become life-threatening rapidly if left untreated.

A 45-year-old man was admitted with shortness of breath and a productive cough and diagnosed with severe community-acquired pneumonia. A computed tomography (CT) of the chest showed that the patient had a complex right-sided pleural effusion suspicious of an empyema. As he was not responding to antibiotics, he was referred for an ultrasoundguided drainage of the effusion. The procedure was performed via a posterior approach using the Seldinger technique. On initial placement of a Kellett needle immediately superior to the rib border under ultrasound guidance, frank blood was aspirated from the pleural cavity. The posterior approach was abandoned and the Kellett needle removed. The procedure was abandoned and a CT of the chest was ordered. This demonstrated no evidence of active hemorrhage, and therefore the patient was returned to the ward for close observation. Two hours later, the patient became hemodynamically unstable with signs of cardiopulmonary compromise. A bedside chest $\mathrm{X}$-ray done showed a large volume right-sided effusion resulting in mediastinal shift. An emergency thoracostomy was performed at the bedside to treat the imminent cardiorespiratory failure. A large quantity of blood was evacuated, but the patient remained tachycardic and hypotensive. An urgent CT showed active contrast extravasation from an intercostal artery at the site of the needle insertion (-Fig. 1). The patient was subsequently transferred to the interventional radiology (IR) suite where an angiogram showed active bleeding from the right seventh intercostal artery. This was successfully embolized using a several small micro coils (-Fig. 2). Post embolization he was managed in the critical care unit. There was difficulty weaning him off the ventilator and he required a tracheostomy. After a protracted stay in the critical care unit and subsequent surgical pleural decortication, he gradually improved and was discharged in a stable condition. A CT done 6 months later showed a right-sided fibrothorax and the patient remains symptomatically well.

Chest drain placement is a common IR procedure and is essential for the treatment of pleural empyemas. Complications occur in 1 to $36 \%$ of patients and can include tube malposition, kinking, tube blockage, dislodgement, and intercostal neurovascular injury. ${ }^{1}$ Direct injuries to the lung, heart or great vessels, esophagus, and diaphragm or subdiaphragmatic organs have been also been reported. ${ }^{2}$ Tension hemothorax is a

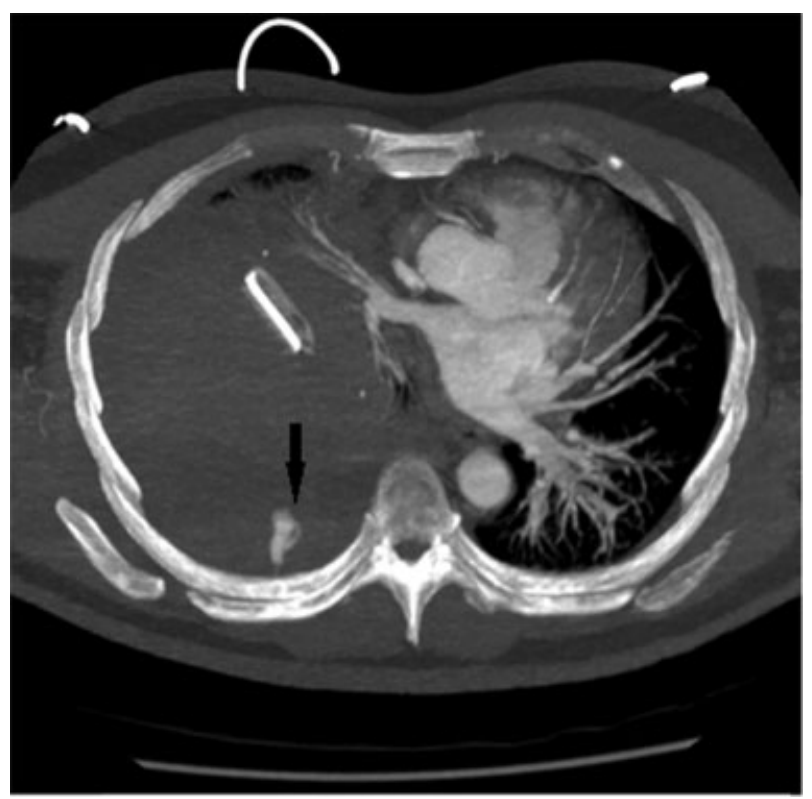

Fig. 1 Maximum-intensity projection CT angiogram showing active contrast extravasation from the right seventh intercostal artery. received

February 14, 2017

accepted after revision

May 1, 2017

published online

September 1, 2017
Dol https://doi.org/

10.1055/s-0037-1603889. ISSN 2457-0214.
Copyright (c) 2017 by Indian Society of Vascular and Interventional Radiology
License terms

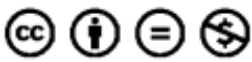




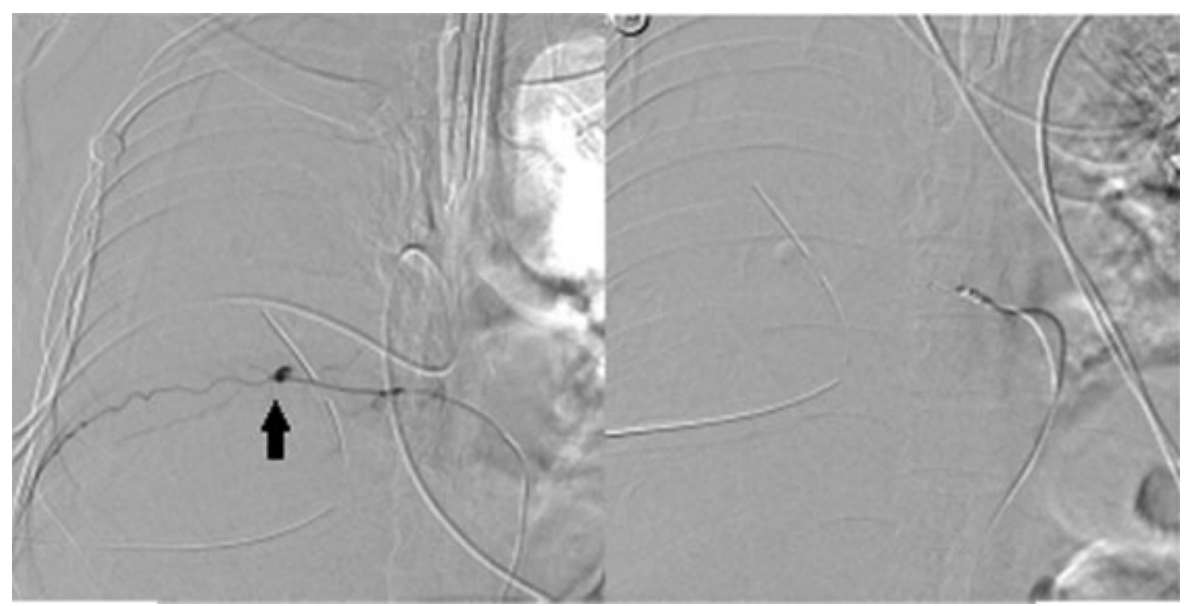

Fig. 2 Digital subtraction angiogram showing the embolization of the bleeding intercostal vessel with micro coils (arrow).

rare complication that can be life threatening as it can cause significant and rapid cardiopulmonary compromise. It can present anywhere from immediately to up to 4 days from the initial trigger. ${ }^{3}$ There is no consensus on whether to immediately drain an accumulating hemothorax. Any decision should be made at a senior level on a case-by-case basis considering the patient's clinical status, likely source of blood loss, medical background, and proximity to definitive therapeutic facilities.

Several anatomical and physiologic facts increase the risk of causing a hemothorax during chest drain placement. These include the location of the drain (anterior or posterior), size of the drain, and any intrinsic or drug-induced coagulation abnormality. Although it is conventionally taught that using an approach just superior to the upper margin of a rib will avoid injuring the intercostal neurovascular structures, a recent study showed that the course of the intercostal artery can be variable within the first $6 \mathrm{~cm}$ of the spine. ${ }^{4}$ Hence, it is safer to place a drain as far away as possible from the spine.

While surgically placed drains tend to be of a larger caliber, IR placed drains are usually smaller. The TIME1 (Therapeutic Interventions in Malignant Effusion 1) study compared the efficacy of large- (24F) versus small-bore (12F) drains in patients with malignant pleural effusions. ${ }^{5}$ Patients were randomized into two groups either having a $24 \mathrm{~F}$ drain or a $12 \mathrm{~F}$ drain. The failure rates measured at 3 months were higher for the smaller-bore drains being $30 \%$ for the $12 \mathrm{~F}$ drain and $23 \%$ for the $24 \mathrm{~F}$ drain. Still, it is generally accepted that for any indication the smallest size of drain possible should be utilized to minimize the risk of complications. Finally, any coagulation abnormalities should be corrected before drain placement to bring the international normalized ratio (INR) less than 1.5 and platelets more than $50,000 / \mu \mathrm{L}$.

There must be a high index of suspicion for hemothorax and tension hemothorax formation in any patient who develops cardiopulmonary problems post drain placement. Immediate chest X-ray and CT can identify complications and help plan management. In some patients, correction of underlying coagulation abnormalities might cause spontaneous cessation of bleeding whereas others will require angiography and embolization of the bleeding vessel. A second chest drain in another location might be required to relieve pressure symptoms from a large hemothorax, which causes cardiopulmonary compromise.

In conclusion, tension hemothorax can be a life-threatening iatrogenic complication of chest drain placement. Using an approach as anterior as possible and just superior to the rib margin and choosing the smallest-caliber chest drain can reduce the risk of damage to the intercostal neurovascular bundle. In patients who develop cardiopulmonary compromise, it can be managed by additional chest drain placement to reduce intrathoracic pressure and embolization of bleeding vessels.

\section{References}

1 Millikan JS, Moore EE, Steiner E, Aragon GE, Van Way CW III. Complications of tube thoracostomy for acute trauma. Am J Surg 1980;140(06):738-741

2 KW. Complications of thoracostomy. Chest 1991;100(03):886-887

3 Martinez JM, Villanueva AG, Pickering R, et al. Spontaneous hemothorax. Report of 6 cases and review of the literature. Medicine (Baltimore) 1992;71:354-368

4 Helm EJ, Rahman NM, Talakoub O, Fox DL, Gleeson FV. Course and variation of the intercostal artery by CT scan. Chest 2013;143(03): 634-639

5 Rahman NM, Pepperell J, Rehal S, et al. Effect of opioids vs NSAIDs and larger vs smaller chest tube size on pain control and pleurodesis efficacy among patients with malignant pleural effusion: the TIME1 randomized clinical trial. JAMA 2015;314(24):2641-2653 